MELO FILHO, P.A.; DUSI, A.N.; COSTA, C.L.; RESENDE, R.O. Colonização de plantas de alho por Neotoxoptera formosana no DF. Horticultura Brasileira, Brasília, v.23, n.4, p.929-930, out-dez 2005.

\title{
Colonização de plantas de alho por Neotoxoptera formosana no DF
}

\author{
Péricles de A. Melo Filho'; André N. Dusi²; Cláudio Lúcio Costa ${ }^{3}$; Renato de O. Resende ${ }^{3}$ \\ ${ }^{1}$ Universidade Federal Rural de Pernambuco, Depto Agronomia, Dom Manoel de Medeiros s/n 52171-900 Recife-PE; E-mail: \\ pericles@ufrpe.br; ${ }^{2}$ Embrapa Hortaliças, C. Postal 218, 70359-970 Brasília-DF; 3 Universidade de Brasília, Instit. Biologia, 70919-970 \\ Brasília-DF
}

\section{RESUMO}

Plantas de alho da cv. Amarante, cultivadas em casa de vegetação para detecção da ocorrência de viroses, foram naturalmente infestadas por afídeos de coloração escura durante a primavera de 2001. Com o objetivo de identificar a espécie em questão foram coletados indivíduos alados, capturados com armadilha constituída por bandeja amarela com água, além de formas ápteras. A identificação da espécie foi feita segundo a chave descritiva elaborada por Blackman \& Eastop (1984) e por comparação com espécimes de Neotoxoptera formosana e $N$. oliveri da coleção do Depto. Fitopatologia da Universidade de Brasília. $\mathrm{O}$ afídeo encontrado em alho pertence à espécie Neotoxoptera formosana Takahashi, 1921.

Palavras-chave: Allium sativum, afídeos.

\begin{abstract}
Colonization of garlic plants by Neotoxoptera formosana in Distrito Federal, Brazil

Garlic plants (cv. Amarante) cultivated during the spring in the greenhouse for detection of viruses, were found to be naturally colonized by a dark aphid. For species identification, specimens of the few alatae individuals collected by pan yellow water traps and many apterae individuals were compared to the species descriptions in Blackman \& Eastop (1984). The specimens were also compared with Neotoxoptera formosana and $N$. oliveri from the aphid collection of the Phytopathology Department of the University of Brasília. The aphid found in the garlic plants belongs to the species Neotoxoptera formosana Takahashi, 1921.
\end{abstract}

Keywords: Allium sativum, aphid.

(Recebido para publicação em 26 de outubro de 2004 e aceito em 3 de agosto de 2005)

$\mathrm{O}$ alho (Allium sativum L.) é uma das hortaliças mais cultivadas no mundo e largamente empregado na culinária brasileira. No Brasil, a cultura destaca-se como uma das cinco hortaliças de maior relevância (RESENDE, 1997). Vários agentes fitopatogênicos, especialmente os vírus, provocam redução na produtividade de bulbos. Entre os vírus de maior importância encontramse os potyvírus Onion yellow dwarf virus (OYDV) e Leek yellow stripe virus (LYsV), o carlavírus Garlic common latent virus (GarCLV) e várias espécies de allexivírus, todos transmitidos por afídeos (CONCI et al., 1999), com exceção dos allexivírus que são transmitidos por ácaros. Desses, apenas OYDV isoladamente chega a causar perdas na produção de bulbos de até $50 \%$ (WALKEY; ANTILL, 1989).

Plantas de alho são constantemente visitadas por diversas espécies de afídeos e entre eles são encontrados: Lipaphis sp. (Mordvilko), Rhopaloshiphum sp. (Koch), Aphis sp. (L.), Geopenphigus sp. (Hille), Myzus sp. (Passerini), Hyperomyzus sp. (Börner) e Neotoxoptera sp. (Theobald) (MELO FILHO et al., 2000; MELO FILHO et al., 2002). Mais de oitenta e seis espécies de vírus são transmitidas por afídeos (PAIVA; KITAJIMA, 1985).

Blackman e Eastop (1984) relataram a ocorrência de Neotoxoptera formosana em plantas do gênero Allium no Japão, China, Taiwan, Coréia, Austrália, Nova Zelândia, Hawai e América do Norte. No Brasil não há relato de sua ocorrência em A. sativum. O presente trabalho teve como objetivo a detecção da ocorrência de viroses em plantas de alho naturalmente infestadas por afídeos.

\section{MATERIAL E MÉTODOS}

Plantas de alho da cv. Amarante foram cultivadas durante a primavera, em casa de vegetação na Embrapa Hortaliças, para estudos de viroses. Durante o cultivo ocorreu infestação natural por uma espécie de afídeo de coloração escura. As plantas colonizadas foram transportadas para insetário com tela anti-afídeo para manutenção das populações e posterior captura de adultos com uso de armadilha constituída por bandeja amarela com água e detergente. Foram preparadas lâminas semipermanentes para observação da morfologia dos espécimes com auxílio de microscópio composto. Os espécimes foram comparados com as descrições encontradas em Blackman e Eastop (1984) e Costa et al. (1993), com espécimes encontrados na coleção de afídeos do Departamento de Fitopatologia da Universidade de Brasília, além de registros fotográficos das principais características morfológicas dos espécimes através do uso de microscópio esteroescópio Zeiss, quer sejam: $N$. formosana (adultos ápteros de coloração magenta, vermelha a preto, antena escura da base ao ápice, sifúnculo escuro ou pálido só em formas jovens, forma alada vermelho escura ou preta, com bordado em toda extensão das nervuras das asas); $N$. oliveri (adultos ápteros de coloração vermelha escura, antena com base clara e segmentos terminais negros, sifúnculo pálido em adultos, forma alada vermelho escura a preta, com bordados estreitos na base e no ápice) (Blackman; Eastop, 1984).

\section{RESULTADOS E DISCUSSÃO}

As colônias de afídeos detectadas sobre as plantas de alho eram de colo- 


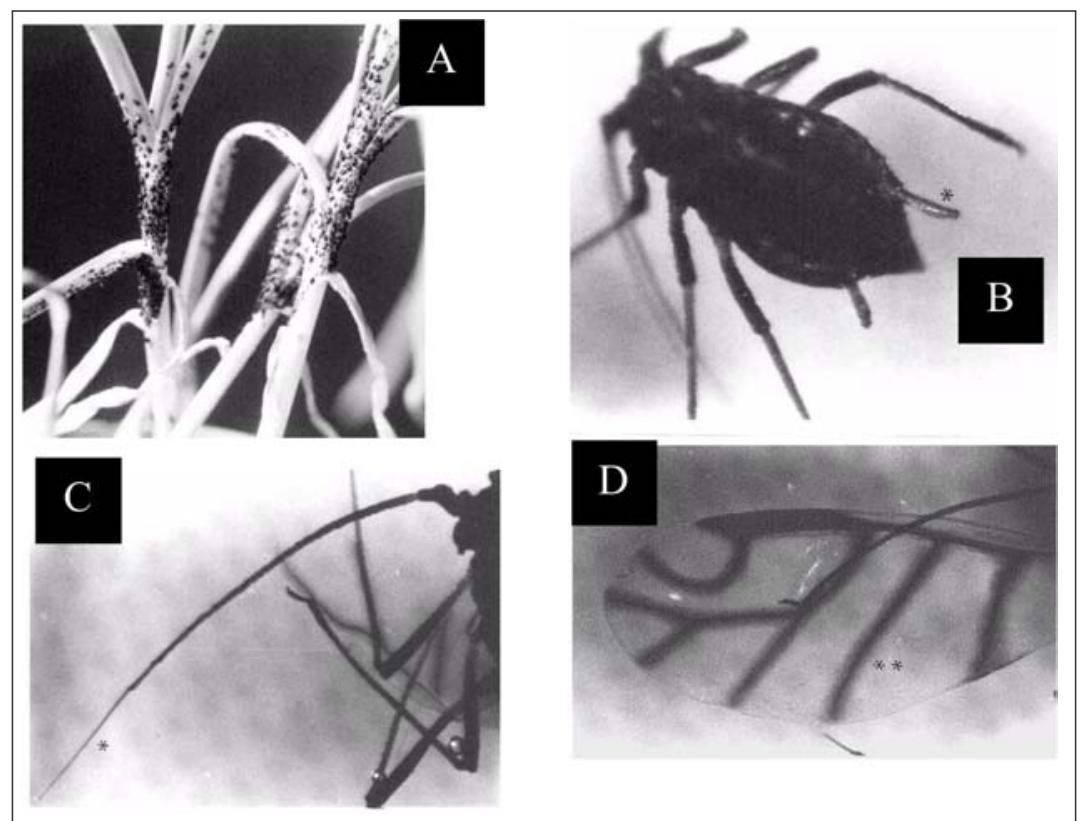

Figura 1. Colonização por Neotoxoptera formosana sobre plantas de alho no Brasil: A) Agrupamento dos espécimes na porção mediano-basal das folhas; B) Forma aptera apresentando forma ovalada, coloração negra e sifúnculo* escuro e clavado; C) Antena apresentando longo processo terminalis*; D) Forma alada apresentando decoração ao longo de todo o comprimento das nervuras das asas**. Brasília, Embrapa Hortaliças, 2001.

ração escura e com a maioria dos espécimes localizados da porção mediana para a basal das folhas (Figura 1A). Os espécimes ápteros, quando observados ao microscópio estereoscópio, apresentaram forma ovalada e de coloração negra a magenta, com sifúnculo clavado também de coloração escura (Figura 1B), porém pálido nas formas jovens. Estas características concordam com aquelas descritas por Blackman e Eastop (1984) a respeito das espécies de afídeos que colonizam plantas de alho.

A antena é de coloração escura desde a base até o ápice. Essa característica permite a separação entre Neotoxoptera formosana e $N$. oliveri (Blackman; Eastop, 1984). Há na antena a presença de longo processo terminalis (Figura 1C). As asas apresentam as nervuras uniformemente bordadas em toda a sua extensão (Figura 1D), sendo esta outra importante característica que separa Neotoxoptera formosana de N. oliveri (Blackman; Eastop, 1984). Isto reforçou a hipótese de se tratar da espécie Neotoxoptera formosana.

De acordo com Sako et al. (1990), N. formosana é comprovadamente transmissor de Garlic latente vírus (GarLV). No trabalho os autores comprovaram transmissão desse vírus para plantas de Allium chinese. Isso torna esse afídeo potencialmente transmissor dessa espécie de vírus para outras espécies do gênero Allium.

Com base nas observações registradas e descrições encontradas na chave de classificação de famílias e subfamílias descrita em Costa et al. (1993) e em Blackman e Eastop (1984), pode-se concluir que se trata da ocorrência de $N$. formosana sobre alho no Brasil. Este é o primeiro relato da colonização de $N$. formosana sobre plantas de alho no Brasil.

\section{LITERATURA CITADA}

BLACKMAN, R.L.; EASTOP, V.F. Aphids on the world's crops: an identification guide. New York: John Wiley \& Sons, 1984. 466 p.

CONCI, V.C.; CANAVELLI, A.E.; LUNELLO, P.A.; CAFRUNE E.E. Mosaico del ajo. In: Projecto de investigaciones en fitovirologia. Instituto de Fitopatologia y Fisiologia Vegetal IFFIVE y Instituto Nacional de Tecnologia Agropecuária - INTA. Argentina, 1999. p.1-6.

COSTA, C.L.; EASTOP, V.F.; BLACKMAN, R.L. Brazilian Aphidoidea: I. Key to families, subfamilies and account of the phylloxeridae. Pesquisa Agropecuária Brasileira. Brasília, v.28, n.2, p.197-215, 1993.

MELO FILHO, P.A.; TANABE, C.M.N.; DUSI, A.N.; TORRES, A.C.; ÁVILA, A.C.; BUSO, J.A.; RESENDE, R.O. Degeneration of garlic (Allium sativum L.) plants caused by virus infection after four sequential field generations. Virus Reviews \& Research. v.5, n.2, p.198, 2000.

MELO FILHO, P.A.; DUSI, A.N.; BUSO, J.A.; TORRES, A.C.; ÁVILA, A.C.; RESENDE, R.O. Degeneration of garlic plants caused by virus infection after five sequential field generations. Summa Phytopathologica, Piracicaba, v.28, n.1, p.141, 2002.

RESENDE, G.M. Desempenho de cultivares de alho no norte de Minas Gerais. Horticultura Brasileira, Brasília, v.15, n.2, p.127-130, 1997.

PAIVA, F.A.; KITAJIMA, E.W. Doenças provocadas por vírus e por patógenos que causam sintomas semelhantes às viroses. Informe Agropecuário, Belo Horizonte, v.11, n.122, p.2936, 1985.

SAKO, I.; TANIGUCHI, T.; OSAKI, T.; INOUYE, T. Transmission and translocation of garlic latent virus in rakkyo (Allium chinense $\mathrm{G}$. Don). Proceedings of the Kansai Plant Protection Society. n. 32, 21-27, 1990.

WALKEY, D.G.A.; ANTILL, D.N. Evaluation of viruses-free and virus-infected garlic (Allium sativum L.). Journal of Horticultural Science. v.64, n. 1, p.60, 1989. 